\title{
List organization and recognition memory
}

\author{
JOHN F. HALL \\ Pennsylvania State University, University Park, Pennsylvania 16802
}

\begin{abstract}
Some investigators have been unable to find that list organization aids recognition, although it does aid recall, thus lending support to a model of memory that assumes that the memorial processes involved in recall differ from those operating in recognition. Other experimenters, however, have found organization to have a facilitating effect on recognition. The present study examined recognition performance using organized and unrelated word lists, with two types of distractors being used. Results indicated that organization aided recognition, regardless of the type of distractor employed.
\end{abstract}

In positing that recognition and recall measures represent different memorial processes, Kintsch (1977) and McCormack (1972) have supported their position by indicating that these measures are differentially influenced by list organization; more specifically, the presentation of an organized list of words, when compared with an unorganized list, results in superior recall, but recognition performance is the same for both lists.

Experiments examining this position have produced mixed findings. Bruce and Fagan (1970), Cofer (1967), and Kintsch (1968), supporting the different memorial process position, were unable to find recognition differences between organized and unorganized lists. But D'Agostino (1969) and Jacoby (1972) were able to obtain superior recognition memory for organized word lists. The more recent studies of Connor (1977) and Neely and Balota (1981) have also provided mixed findings. Connor (1977, Experiment 1) was unable to demonstrate recognition superiority for organized lists, but Neely and Balota (1981), using a within-subjects type of experimental design, were able to obtain superior recognition performance for those items that were organized.

In view of the controversial findings, the present study was a further attempt to examine the role of list organization on recognition. ${ }^{1}$ In an earlier study examining recognition as a function of high- and low-frequency words, Hall (1979) found an interaction between this variable and the characteristics of the distractors used in the recognition test. Since there is the possibility that such an interaction may also exist between recognition and list organization, the distractors used in this study were varied, being either (1) conceptually or associatively related or (2) unrelated to the target words.

\section{METHOD}

\section{Subjects}

Eighty subjects ( 20 per group) were obtained from introductory psychology classes and were randomly assigned to one of four experimental conditions: (1) presentation of an organized word list or (2) an unrelated word list using either (a) conceptual or associative or (b) unrelated distractors in the recognition test.

\section{Materials}

An organized list of 42 words was constructed by randomly selecting 3 words from the 6 most frequently cited in each of 14 conceptual categories provided by Shapiro and Palermo (1970). An unrelated list of words was made up by using 42 words obtained from the stimulus words used by Palermo and Jenkins (1964) and Shapiro and Palermo (1968) in their establishment of word association norms. In order to insure list equivalency on other than the organizational variable, the words on both lists were virtually identical with regard to ThorndikeLorge (1944) frequency. In order to increase the organization of the experimental material, blocked presentation of the words was employed. Each set of three words belonging to a conceptual category was placed on a single $3 \times 5$ in. card. The unrelated list cards also contained 3 words/card.

Recognition memory was measured by combining each target or list word with a distractor, thus producing a 42-item two-choice recognition test. One test used distractors that were conceptually or associatively related to the target words. With the organized word list, these distractors were obtained by using the three words not previously selected from the six most frequently cited in each of the 14 conceptual categories provided by Shapiro and Palermo (1968). Distractors for the target words making up the unrelated word list were associatively related and obtained by using one of the most frequent free association responses made to each of the 42 stimulus words, as indicated by Palermo and Jenkins (1964) and Shapiro and Palermo (1970). Unrelated distractors used on the recognition test for both the organized and unorganized word lists were selected from Thorndike and Lorge (1944), with each word judged to be unrelated to the target word. Although the two sets of distractors used with each list of target words differed in their relatedness to the organizational variable, every effort was made to make them equivalent on other word attributes. Thus, related and unrelated distractors used with the organized list or with the unorganized list each began with the same letter, generally contained the same number of letters, and were similar with regard to their Thorndike-Lorge (1944) frequency count.

\section{Procedure}

Subjects were run in groups of four, five, or six. After being given general instructions concerning the nature of the task, each subject was given a pack of cards containing the organized or unrelated list words. On signal, subjects were given $10 \mathrm{sec}$ to study the words on the first card, following which they were asked to turn to the next card for another 10-sec study period, 
Table 1

Recognition as a Function of List Organization and the Nature of the Distractors

\begin{tabular}{ccc}
\hline & \multicolumn{2}{c}{ Type of Distractor } \\
\cline { 2 - 3 } Type of List & Similar & Unrelated \\
\hline Organized & 39.25 & 41.55 \\
Unrelated & 33.80 & 36.90 \\
\hline
\end{tabular}

and so on. After the subjects had studied all of the words, the experimental material was collected and appropriate recognition tests were distributed. Subjects were permitted to work at their own speed but were asked to guess if they were not sure which item in a particular pair was correct.

\section{RESULTS AND CONCLUSIONS}

Recognition performance, as indicated in Table 1, was influenced by list organization, with subjects being able to recognize significantly more words from the organized list than from the list containing unrelated words $[F(1,76)=69.48, p<.01]$. This finding, in accord with the results of D'Agostino (1969), Jacoby (1972), and Neely and Balota (1981), was obtained regardless of whether the distractors employed were unrelated or semantically related to the target items, thus providing generality to the basic conclusion that recognition is influenced by list organization.

Recognition differences were obtained as a function of the kind of distractor that was used $[F(1,76)=19.86$, $\mathrm{p}<.01]$, a finding in keeping with the results of other investigators (e.g., Anisfeld \& Knapp, 1968; Postman, 1951). The significant interaction obtained between word frequency and type of distractor noted in Hall's (1979) earlier study was not, however, found. Thus, we cannot single out the type of distractor employed as contributing to the mixed findings obtained in earlier recognition and list organization studies, but we must search elsewhere for an explanation.

\section{REFERENCES}

Anisfeld, M., \& KNAPP, M. Association, synonymity, and directionality in false recognition. Journal of Experimental Psychology, 1968, 77, 171-179.

Bruce, D., \& Fagan, R. L. More on the recognition and free recall of organized lists. Journal of Experimental Psychology, 1970, 85, 153-154.

CoFer, C. N. Does conceptual organization influence the amount retained in immediate free recall? In B. Kleinmuntz (Ed.), Concepts and the structure of memory. New York: Wiley, 1967.

Connor, J. M. Effects of organization and expectancy on recall and recognition. Memory \& Cognition, 1977, 5, 315-318.

D'Agostino, P. R. The blocked-random effect in recall and recognition. Journal of Verbal Learning and Verbal Behavior, $1969,8,815-820$.

Hall, J. F. Recognition as a function of word frequency. American Journal of Psychology, 1979, 92, 497-505.

JACOBY, L. L. Effects of organization on recognition memory. Journal of Experimental Psychology, 1972, 92, 325-331.

Kintsch, W. Recognition and free recall of organized lists. Journal of Experimental Psychology, 1968, 78, 481-487.

Kintsch, W. Memory and cognition. New York: Wiley, 1977. Mandle R, G. Organization and recognition. In E. Tulving \& W. Donaldson (Eds.), Organization of memory. New York: Academic Press, 1972.

Mandler, G., Pearlstone, Z., \& Koopmans, H. S. Effects of organization and semantic similarity on recall and recognition. Journal of Verbal Learning and Verbal Behavior, 1969, 8, 410-423.

McCormack, P. D. Recognition memory: How complex a retrieval system? Canadian Journal of Psychology, 1972, 26, 19-41.

NeEly, J. H., \& BAlota, D. A. Test-expectancy and semanticorganization effects in recall and recognition. Memory \& Cognition, 1981, 9, 283-300.

Palermo, D. S., \& Jenkins, J. J. Word association norms: Grade school through college. Minneapolis: University of Minnesota Press, 1964.

Postman, L. The generalization gradient in recognition memory. Journal of Experimental Psychology, 1951, 42, 231-235.

Shapiro, S. I., \& Palermo, D. S. An atlas of normative free association data. Psychonomic Monograph Supplements, 1968, 2, 219-250.

Shapiro, S. I., \& Palermo, D. S. Conceptual organization and class membership: Normative data for representatives of 100 categories. Psychonomic Monograph Supplements, 1970, 3, 107-127.

ThoRndike, E. L., \& LoRge, I. The teacher's word book of 30,000 words. New York: Columbia University Press, 1944.

\section{NOTE}

1. Our concern and experimental procedure have been to use the "traditional" list-learning experiment, in which subjects are asked to learn a list of words that are presented in a fixed order. As Neely and Balota (1981) have acknowledged, organizational effects are well documented when subjects are given the opportunity to manipulate their organization of the material by sorting of presumably "unrelated" words into their own subjectdefined categories (e.g., Mandler, 1972; Mandler, Pearlstone, \& Koopmans, 1969).

(Received for publication May 17, 1982.) 